\title{
Computational water management strategy of Tlawng River Basin using geo-informatics
}

\author{
Lalhmingliana ${ }^{1}$, Ch.Udaya Bhaskara $\mathrm{Rao}^{{ }^{\dagger}}$, Goutam Saha ${ }^{3}$ \\ ${ }^{1}$ Department of Computer Engineering, Mizoram University, Aizawl 796004 \\ ${ }^{2}$ Department of Ceography and Resource Management, Mizoram University, Aizawl 796004. \\ ${ }^{3}$ Department of Information Technology, N.E.H.U, Shillong, Meghalaya 793022
}

\begin{abstract}
Aizawl city is experiencing seasonal water scarcity. Tlawng is the longest River in Mizoram which flows for about $234 \mathrm{~km}$ length in Mizoram in south - north direction and joins the River Barak in Cachar district of Assam state. As Tlawng River is close to the Aizawl city, it will be wise to make some safe and durable strategy for storing rain water safely in predefined reservoirs and use it during hour of needs for domestic and agricultural purposes. In fact, Aizawl city is located within the Tlawng River basin at an average elevation of about 1,200 metres above mean sea level. An attempt has been made in this study for identification of feasible sites for construction of water reservoirs at appropriate locations based on the integration of thematic data on slope, flow accumulation, lithology, drainage density, lineament density and lineament direction using the advanced tools of ArcGIS software. Thirty two ideal sites have been identified in the vicinity of Aizawl city based on the multi-criteria evaluation of the thematic layers.
\end{abstract}

Keywords: Flow accumulation, Flow direction, Geo-informatics, Reservoirs, Thematic data

\section{Introduction}

Water management refers to the judicial use of water resources with an objective to minimize the wastages. India receives huge amount of rainfall during rainy season that often leads to floods causing damage to human habitations, property and sometimes loss of life [1]. In fact, worldwide investigations on water management system has become an important issue since water is an essential resource for the survival of all forms of life and it is going to be scarce day by day. Good water management refers to implementation developmental strategies to store excess water that can be utilized during lean period. Rain water can be harvested during rainy season at suitable locations in and around the catchment which can be used during its scarcity [2]. The point of investigation here is storing the excess water at suitable locations causing minimum damage to ecosystem and maintaining safety. The present study deals with such a problem focussing on a water starved region namely Aizawl, the capital of Mizoram.

The stored water thus collected can be brought to Aizawl through interconnected stream network of the Tlawng River. This strategy

This is an Open Access article distributed under the terms of the Creative Commons Attribution Non-Commercial License (http://creativecommons.org/licenses/by-nc/3.0/) which permits unrestricted non-commercial use, distribution, and reproduction in any medium, provided the original work is properly cited.

Copyright (C) 2020 Korean Society of Environmental Engineers is expected to reduce the chances of flooding and drought in this region as happened several times in the past. The Tlawng River during the past decade had caused flood induced disaster within the vicinity of Aizawl city and hence, water management has become inevitable. The present study is expected to resolve the water scarcity problem of Aizawl to a great extent.

Several methodologies have been employed for identification of suitable sites for the construction of reservoirs [3]. The most conventional method for identifying suitable dam site location is field survey owing to its several advantages. Yet, the primary drawback of this approach is that larger areas cannot be considered and the area for such a site requires the investigation of vast region, therefore inefficient. Highly accurate thematic layers can be generated using the high resolution satellite imagery $[4,5]$ and integrated with more precision using GIS software [6]. Computational analysis of this data by using the advanced techniques of geographical information systems will be helpful for the selection of sites in different site selection strategies. The present study is the first of its kind in this highly rugged terrain to identify the sites which are suitable for the construction of dams.

\footnotetext{
${ }^{\dagger}$ Corresponding author

Email: chegondiu@yahoo.co.in

Tel: +91-9436352455

ORCID: 0000-0003-2328-7510
}

Accepted September 22, 2019 


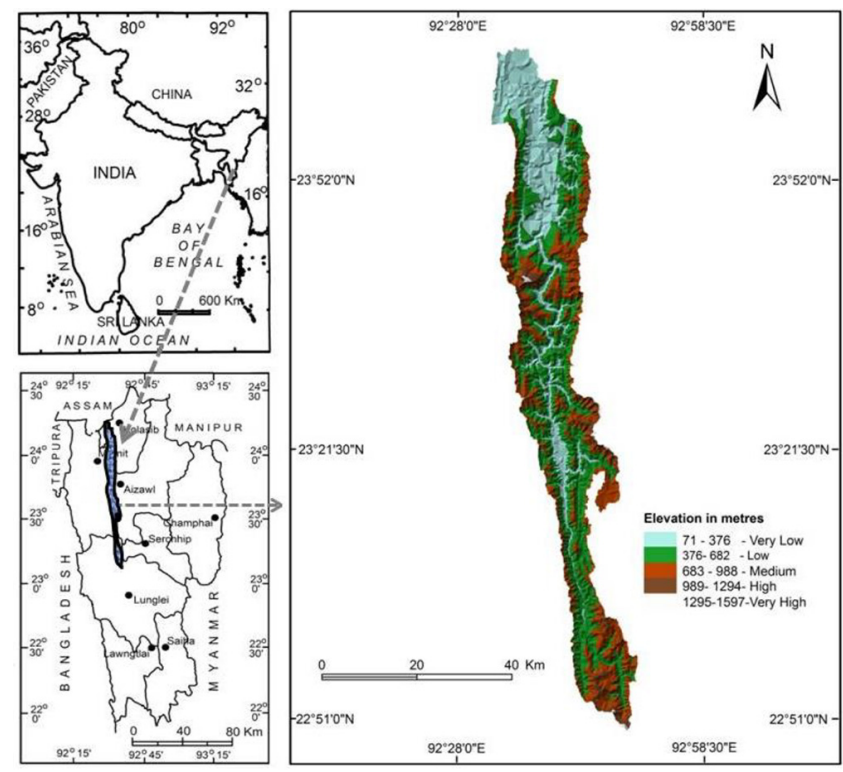

Fig. 1. Location map of the Tlawng River basin.

\subsection{Description of the Study Area}

The Tlawng River basin falls in parts of the districts namely, Kolasib, Mamit, Aizawl, Serchhip and Lunglei in Mizoram. It is a north - south aligned basin located between $92^{\circ} 32^{\prime} 10^{\prime \prime}-92^{\circ} 50^{\prime} 23^{\prime \prime}$ east longitudes and $22^{\circ} 49^{\prime} 58^{\prime \prime}-24^{\circ} 07^{\prime} 18^{\prime \prime}$ North latitudes spreads in an area of about $1,732.72 \mathrm{~km}^{2}$ (Fig. 1). The River Tlawng originates in Zopuii hill near Zobawk village in Lunglei district at an elevation of about 1,395 $\mathrm{m}$ above MSL. The highest elevation of 1,597 is seen in the north-western part and the lowest elevation of 71 $\mathrm{m}$ at its mouth. The River flows in north direction over a length of about $234 \mathrm{~km}$ in Mizoram and joins the Barak River in Cachar district of Assam state. According to the watershed Atlas of India the Tlawng River basin code is 3C2A8. Tut and Teirei are the major tributaries to the Tlawng River. Sandstones, siltstones \& shales, clayey sand, gravel, sand and silt are the major litho-units found in the basin of which sandstones, siltstones and shales spread extensively. The moist tropical type of climate prevails in this region with an average annual rainfall of about $250 \mathrm{~cm}$. (Table S1).

\section{Material and Methods}

Topographical maps of Mizoram published by Survey of India have been used to delineate drainage network of the study area. Drainage density map has been prepared by using the formula of Horton [7]. Faults, fractures and lineaments have been identified on the geocoded satellite image of IRS P6 LISS IV MX (dated 21 February 2018) by visual interpretation and the lineament density has been computed. Land use/ land cover map has been prepared by visual interpretation using the satellite imagery and ground truth verification. ASTER GDEM has been downloaded from NASA website [8] and used to generate slope and flow accumulation by using ArcGIS 9.3 software. Lithology map has been prepared from the geological map published by the Geological Survey of India with ground truth verification. Field investigation has been carried out to measure channel dimensions at selected sites along the Tlawng River. The thematic layers such as slope, lithology, flow accumulation, drainage density and lineament density have been integrated by multi-criteria evaluation using ArcGIS spatial analyst tools to identify suitable dam sites.

\section{Thematic Data}

\subsection{Rainfall}

Rainfall is the most important factor as the availability of ground water depends on it. The area receives an average rainfall of about $183 \mathrm{~cm}$ during the southwest monsoon period from June to September. The rainfall distribution is more or less uniform in the Tlawng River basin (Fig. 2). The southern most part receives high amount of rainfall which ranges between 2,500 and 3,000 $\mathrm{mm}$ whereas the western part receives less than $2,000 \mathrm{~mm}$. Similarly, the northern most part receives above $2,500 \mathrm{~mm}$ of rainfall while in the central part it ranges between $2,000 \mathrm{~mm}$ and $2,500 \mathrm{~mm}$. As a whole rainfall increases towards the southern part of the study area.

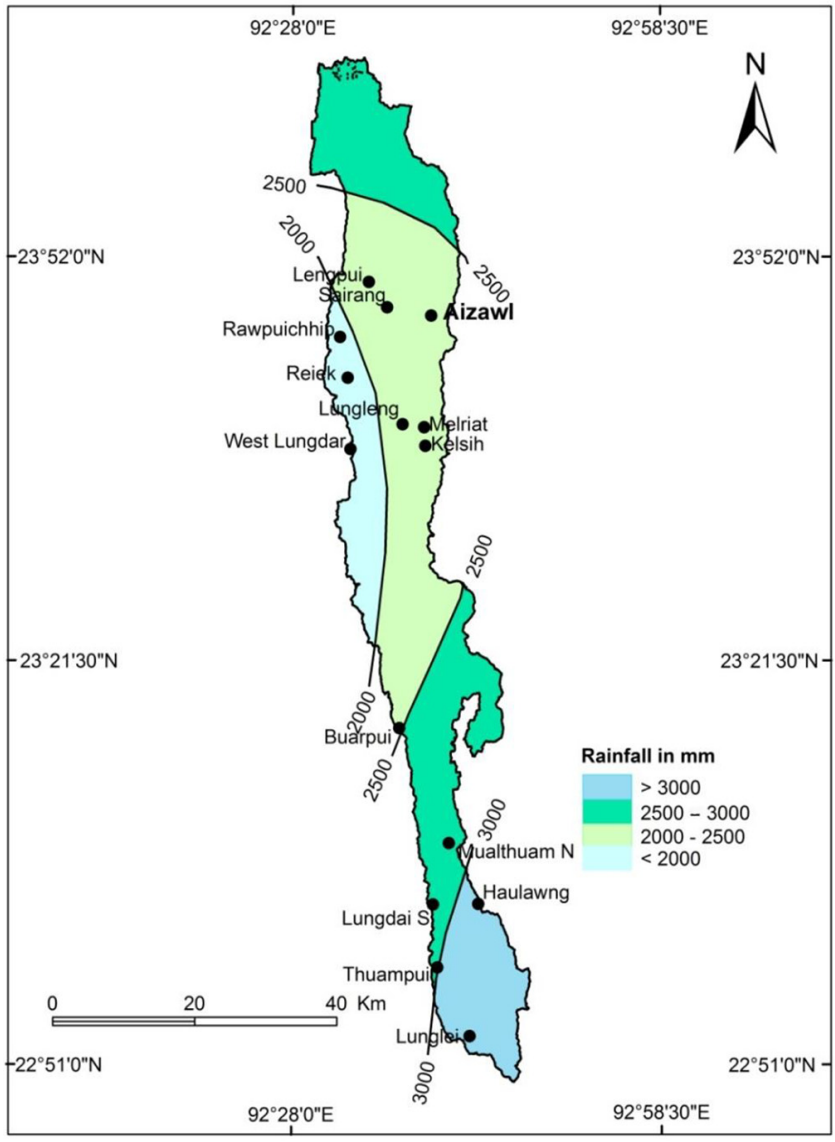

Fig. 2. Rainfall distribution in Tlawng River basin. 


\subsection{Slope}

Slope is the major factor which controls infiltration, runoff and also the intensity of erosion. In fact, the runoff rate in Mizoram is higher than infiltration due to nature of the rock and mostly by steepness of the terrain [9]. It is seen that gentle to moderately sloping areas cover about $705 \mathrm{~km}^{2}$ (40.69\%) of the basin (Table 1). Gentle to moderately steep sloping areas up to 15 which spread in an area of about $1,268.96 \mathrm{~km}^{2}$ (73.24\%) have been given top priority as they are expected to receive and retain more water in the subsurface (Fig. S1).

Table 1. Slope Distribution

\begin{tabular}{lccc}
\hline $\begin{array}{l}\text { Slope } \\
\text { Category }\end{array}$ & Slope Class & $\begin{array}{c}\text { Areal extent } \\
\left(\mathbf{( k m}^{\mathbf{2}} \mathbf{)}\right.\end{array}$ & Percentage \\
\hline 1 & Gently sloping & 250.54 & 14.46 \\
2 & Moderately sloping & 454.46 & 26.23 \\
3 & Moderately steep sloping & 563.96 & 32.55 \\
4 & Steep sloping & 166.33 & 9.60 \\
5 & Very steep sloping & 297.31 & 17.16 \\
\hline
\end{tabular}

\subsection{Lithology}

Nature of the rocks is also the one of the significant factors which affects infiltration in addition to the degree of slope and vegetation cover. As the rocks are sedimentary nature there is a wide scope for infiltration in the area. A major part of the basin of about $99.27 \%\left(1,719.97 \mathrm{~km}^{2}\right)$ is covered by sandstones, siltstones \& shales. Siltstones, shales and clayey sands have been given top priority due to their high water retention capacity and less permeable [10]. (Table S2 and Fig. S2).

\subsection{Flow Accumulation}

Flow accumulation is the most important factor as it represents the areas of flow. High flow, medium flow, low flow and non-flow areas can be depicted on flow accumulation raster. Non flow areas are topographically high without any channel development whereas the high flow areas are the channels of actual flow like well-developed streams. The water storage capacity of streams depends up on the channel dimensions like depth, width and gradient. Siltation may reduce the storage capacity as well as the carrying capacity. In fact, the storage capacity of a channel varies with its morphology which is dependent upon the topography of the adjoining areas.

The maximum flow accumulation of the Tlawng River was estimated to be $205,431 \mathrm{~m}^{3}$ in its lower reaches where the channel width and depth are $53 \mathrm{~m}$ and $36 \mathrm{~m}$, respectively, with a gentle gradient. Similarly, the maximum flow accumulation in its upper stream section at an altitude of $546 \mathrm{~m}$ above MSL is about 2,139 $\mathrm{m}^{3}$ where the channel width and depth are $12 \mathrm{~m}$ and $21 \mathrm{~m}$, respectively, with moderate to steep gradient. There may be several areas along the streams which have high flow accumulation depending upon the channel dimensions and inflow. It is about 10,000 $\mathrm{m}^{3}$ on an average in its middle reaches as the channel gradient is gentle to moderate and steep at some sections for a total length of $45 \mathrm{~km}$ as seen along the main River channel. The areas with high flow accumulation between 50,000 $\mathrm{m}^{3}$ and 205,431 $\mathrm{m}^{3}$ have been given top priority considering the channel dimensions and slope of the neighbouring areas (Fig. S3 and Table S5).

\subsection{Drainage Density}

Drainage density is one of the significant factors which depict the areas of the density of channel network in unit area. It is the ratio of stream length of all orders in a basin to the area of the basin [11].

The River has very good network of streams though 1st and 2nd order streams flow at higher degree of slope between $15^{\circ}$ and $30^{\circ}$ and above which occupy higher elevations ranging from 398 $\mathrm{m}$ to $750 \mathrm{~m}$ in the basin. In the Tlawng River basin the drainage density ranges between 7.77 to $10.38 \mathrm{~km} / \mathrm{km}^{2}$ (Fig. S4). The high and very high density areas range from 9.36 to $9.88 \mathrm{~km} / \mathrm{km}^{2}$ and 9.89 to $10.38 \mathrm{~km} / \mathrm{km}^{2}$ respectively, which occupy an area of about $150.38 \mathrm{~km}^{2}$ as seen in the central parts of the basin have been given top priority (Table S3). The medium drainage density class which spread in an area of about $661.37 \mathrm{~km}^{2}$ (38.18\%) in the northern, central and southern parts have been given medium priority. Similarly, low and very low classes of drainage density seen extensively in an area of $920.66 \mathrm{~km}^{2}$ have been given least priority though it occupies large area taking all other factors into consideration. Though, lithology is more or less uniform there is a wide variation in drainage density due to the other factors like slope and also the ongoing tectonic activity. In fact, slope has strong control over drainage network due to the highly rugged nature of the terrain.

\subsection{Lineament Density}

Lineaments are usually straight or sometimes curvi-linear features of the earth surface representing fractures, joints or faults in the bedrock [12]. Lineaments are comparatively longer than faults and fractures [13].

These are the tectonic features which play a major role in water discharge and also recharge of ground water as they act as conduits. Faults and fractures in the study area are oriented in definite directions like N-S, NE-SW and E-W which indicate the nature of ongoing tectonic activity. A majority of the streams in the basin are controlled by the active faults and fractures.

The lineament density in this basin ranges from 0.163 to 0.491 $\mathrm{km} / \mathrm{km}^{2}$ (Table S4 and Fig. S5). The areas with medium to high lineament density (0.164-0.491) occur in an area of about 873.75 $\mathrm{km}^{2}$ (50.43) particularly in the middle parts of the basin have been given top priority as they enhance the water recharge capacity of reservoirs. Among the total 98 lineaments identified in the study area, $42 \%$ fall under low density and $33 \%$ in medium density areas. Though, majority of the lineaments fall under low to medium classes, its length is comparatively lesser than the lineaments present in high density class.

\subsection{Land Use/Land Cover}

Land use and land cover are the two important physical factors which show the human interaction with the surrounding environment and the dynamics of vegetation. Land cover plays a vital role in developmental planning of any region and at the same 
Table 2. Land Use/ Land Cover Statistics of Tlawng River Basin

\begin{tabular}{lcc}
\hline Land use/ Land cover class & Areal extent $\left(\mathbf{k m}^{2}\right)$ & Percentage \\
\hline $\begin{array}{l}\text { Built-up land } \\
\text { Village/Town/City }\end{array}$ & 25.89 & 1.49 \\
Agricultural land & & \\
$\quad$ Wet rice cultivation & 1.89 & 0.11 \\
$\quad$ Agriculture Plantation & 4.69 & 0.27 \\
Forest & & \\
Dense & 214.48 & 12.38 \\
Medium dense & 228.61 & 13.19 \\
Less dense & 299.53 & 17.29 \\
Forest Plantation & 7.48 & 0.43 \\
Bamboo Forest & 589.58 & 34.03 \\
Wasteland & & \\
Land with scrub & 22.98 & 1.33 \\
Barren rocky areas & 11.49 & 0.66 \\
Water bodies & & \\
River & 9.7 & 0.56 \\
Shifting cultivation & & 5.32 \\
Current & 92.18 & 100.93 \\
Abandoned & 224.1 & \\
Total & 1732.6 & \\
\hline
\end{tabular}

time it has both positive and negative impacts on all natural processes. The land use and land cover map of the watershed shows several distinct units which have a great influence in the dam site selection (Table 2 and Fig. S6). About 77.32\% (1,339.68 $\mathrm{km}^{2}$ ) of the basin is covered by forest with varied intensities. Built-up land which includes settlements and roads occupy an area of 25.89 $\mathrm{km}^{2}$. Wet rice cultivation is practiced in small extent only along the low lying River banks particularly in the downstream areas of Tlawng River. Shifting cultivation occupies an area of 316.28 $\mathrm{km}^{2}$ of which about $92.18 \mathrm{~km}^{2}$ (5.32\%) is under current cultivation. The abandoned shifting cultivation which spreads in an area of about $224.10 \mathrm{~km}^{2}$ over the steep slopes is prone to severe soil erosion causing heavy siltation in the downstream areas and also along the valley sides. Barren rocky areas are seen in the steep sloping areas and also along the steep River banks at places. Agricultural lands, water bodies, shifting cultivation and wasteland feature such as land with or without scrub have been given top priority.

\section{Results and Discussion}

The thematic data on slope, flow accumulation, lithology, drainage density and lineament density have been selected for integration with the predefined theme weight as shown in Table 3 and Fig. 3 to identify feasible sites for water storage. The criteria used for the selection of the sites are gentle to moderately steep sloping areas adjacent to 3rd and 4th order streams composed of siltstone, shale and clayey sand with high flow accumulation ranging between $50,000-2,05,431 \mathrm{~m}^{3}$ in the vicinity of settlements. The thematic data has been integrated with the help of spatial analyst tools as per the criteria defined. The top priority has been given to slope and flow accumulation as they are the decisive factors of water storage in Mizoram due to ruggedness of the terrain. The orientation of faults and fractures have been analysed thoroughly while proposing dam sites as their orientation sometimes may damage the entire structure due to strong ongoing tectonic activity. It is also possible that landslide prone areas also might damage the structure as the terrain is fragile with steep slopes. A total of 32 ideal sites have been identified in and around the $3^{\text {rd }}$ and $4^{\text {th }}$ order streams in the vicinity of Aizawl city considering all the topographic factors (Fig. S7, Fig. 4, Table 4). The selected sites range their elevation from 398 to $988 \mathrm{~m}$ above mean sea level. It is seen in Mizoram that the rate of erosion and siltation in reservoirs and River channels is high as the topography is immature

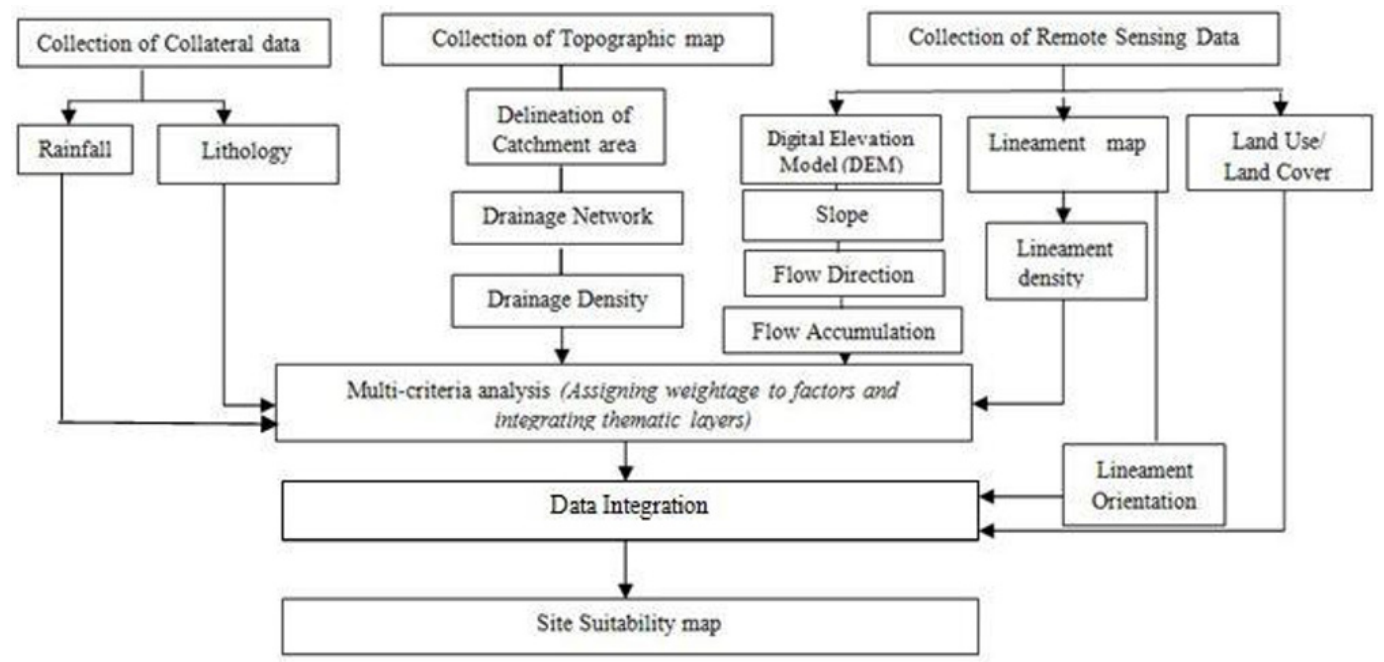

Fig. 3. Work flow. 
Table 3. Ranking of Factors

\begin{tabular}{|c|c|c|c|c|}
\hline Theme / Physical Factor & Sub-Class & Category & Rank & Theme Weight (\%) \\
\hline \multirow{4}{*}{ Rainfall (mm) } & $>3,000$ & Very Good & 1 & \multirow{4}{*}{10} \\
\hline & $2,500-3,000$ & Very Good & 1 & \\
\hline & $2,000-2,500$ & Good & 2 & \\
\hline & $<2,000$ & Moderate & 2 & \\
\hline \multirow{5}{*}{ Slope (\%) } & $0-5$ & Very Good & 1 & \multirow{5}{*}{25} \\
\hline & $5-10$ & Good & 2 & \\
\hline & $10-15$ & Moderate & 3 & \\
\hline & $15-30$ & Poor & 4 & \\
\hline & $>30$ & Very Poor & 5 & \\
\hline \multirow{3}{*}{ Flow Accumulation $\left(\mathrm{m}^{3}\right)$} & $50,000-205,431$ & Very Good & 1 & \multirow{3}{*}{20} \\
\hline & Up to 50,000 & Moderate & 3 & \\
\hline & 0 & Very Poor & 5 & \\
\hline \multirow{4}{*}{ Lithology } & Fine-grained sandstone and shale & Moderate & 3 & \multirow{4}{*}{10} \\
\hline & Siltstone-shale & Good & 2 & \\
\hline & Clayey sand & Very Good & 1 & \\
\hline & Gravel, sand \& silt & Very Poor & 5 & \\
\hline \multirow{5}{*}{ Drainage Density $\left(\mathrm{km} / \mathrm{km}^{2}\right)$} & Very Low $(7.77-8.29)$ & Very Poor & 5 & \multirow{5}{*}{15} \\
\hline & Low $(8.30-8.82)$ & Poor & 4 & \\
\hline & Medium (8.83 - 9.35) & Moderate & 3 & \\
\hline & High $(9.36-9.88)$ & Good & 2 & \\
\hline & Very High (9.86 - 10.38) & Very Good & 1 & \\
\hline \multirow{3}{*}{ Lineament Density $\left(\mathrm{km} / \mathrm{km}^{2}\right)$} & Low $(0.00-0.163)$ & Moderate & 3 & \multirow{3}{*}{10} \\
\hline & Medium $(0.164-0.327)$ & Good & 2 & \\
\hline & High $(0.328-0.491)$ & Very Good & 1 & \\
\hline \multirow{8}{*}{ Land Use/ Land cover } & Built-up land & Poor & 4 & \multirow{8}{*}{10} \\
\hline & Agricultural land & Very Good & 1 & \\
\hline & Forest & Poor & 4 & \\
\hline & Wasteland (Land with scrub) & Very Good & 1 & \\
\hline & Wasteland (Barren rocky area) & Poor & 4 & \\
\hline & Water bodies (River) & Very Good & 1 & \\
\hline & Shifting cultivation (Current) & Very Good & 1 & \\
\hline & Shifting cultivation (Abandoned) & Very Good & 1 & \\
\hline
\end{tabular}

with high relief [9]. It has been established that runoff is less in circular basins than elongated basins [14]. In fact, siltation is controlled by basin characteristics such as topography, shape, degree of slope, velocity of flow and drainage pattern. It has been observed that the drainage pattern is mostly dendrite but trellis and parallel types also occur at several places as the streams are controlled by the structures developed by the ongoing tectonic activity.

The Tlawng River basin is highly elongated in addition to the physical factors like high relief with steep slopes and sedimentary rocks which resulted in high rate of siltation of about 18,210 ha.m/100 $\mathrm{km}^{2} /$ year [9]. All the identified sites are prone to erosion than sedimentation as they occupy topographically higher elevations. However, it is also possible that siltation is high at higher elevations due to ongoing shifting cultivation as in Teirei River basin which resulted in severe soil loss of about 80 ton $\mathrm{ha}^{-1} \mathrm{ya}^{-1}$ [15]. It has been observed in Tuirini watershed that the terrain which ranges from $15^{\circ}$ to $45^{\circ}$ is prone to more erosion [16]. The high relief and steep sloping areas have been subjected to high rate of erosion in Tut River basin [17]. Similar physical conditions exist in the Tlawng River basin also which might lead to high rate of erosion at higher elevations and sedimentation in low lying areas. Therefore, the studies provide useful input in constructing dams to minimize siltation. 
Table 4. Location of Proposed Water Harvesting Structures

\begin{tabular}{|c|c|c|c|}
\hline Location & Longitude & Latitude & Elevation (m) \\
\hline 1 & 92о 42’ 09” & 23o 46’27” & 496 \\
\hline 2 & 92o 42’ 53” & 23o 46’22” & 592 \\
\hline 3 & 92o 43’47” & 23o 45’ 57”' & 789 \\
\hline 4 & 92o 42’ $57^{\prime \prime}$ & 23 o $45^{\prime} 45^{\prime \prime}$ & 538 \\
\hline 5 & $92042 ’ 23 ”$ & 23o 46’ 23”' & 447 \\
\hline 6 & 92o 42’ 23” & 23o 45’ 53” & 398 \\
\hline 7 & 920 40' 40" & 23o 45 ' $12 ”$ & 789 \\
\hline 8 & 920 41'40”' & 23o 45' 29”' & 618 \\
\hline 9 & 920 42’ 28”' & 23 o 45’27” & 648 \\
\hline 10 & 92o 42' $06^{\prime \prime}$ & 23o 45’ $02 ”$ & 526 \\
\hline 11 & 92o 42’ 42” & 23o 45’ 0” & 687 \\
\hline 12 & $92040 ’ 38 ”$ & 23o 44' 36”' & 941 \\
\hline 13 & 920 41' 26" & 23o 44' 45”' & 943 \\
\hline 14 & 92o 42’ 02” & 23o 44' 35”' & 875 \\
\hline 15 & 92o 42' 05” & 23o 44' 23” & 937 \\
\hline 16 & 920 42’ 25” & 23o 44' 04 "' & 979 \\
\hline 17 & 92o 41' 32” & 23o 44' $15^{\prime \prime}$ & 962 \\
\hline 18 & $92040 ’ 45^{\prime \prime}$ & 23o 44' 04” & 813 \\
\hline 19 & 92o 41’03” & 23o 43' 29”' & 775 \\
\hline 20 & 92o 41' 56" & 23o 43' 28”' & 790 \\
\hline 21 & 92o 42’ 46” & 23o 43’ 38” & 913 \\
\hline 22 & 92o 42’ 39” & 23o 42' 57”' & 988 \\
\hline 23 & 92o 41'42”' & 23o 43’02” & 918 \\
\hline 24 & 92o 40’51” & 23o 42' 54”' & 459 \\
\hline 25 & 92о 41' 39”' & 23o 42' 30”' & 641 \\
\hline 26 & 92o 42’ 43” & 23o 42' 28”' & 841 \\
\hline 27 & 92o 41' 50" & 23o 41' 59”' & 869 \\
\hline 28 & 92o 41’ $02 ”$ & 23o 42' 18”' & 424 \\
\hline 29 & 92o 41' 05” & 23o 41'43”' & 616 \\
\hline 30 & 92o 41' 24” & 23o 41' 24”' & 682 \\
\hline 31 & 92o 41' 59”' & 23o 41' 32”' & 644 \\
\hline 32 & 92o 42' 37” & 23o 41' 54”' & 875 \\
\hline
\end{tabular}

\section{Conclusions}

Though the present study identified several potential sites for rain water harvesting $(\mathrm{RWH})$, only 32 highest ranked sites have been recommended in the vicinity of Aizawl city. Interconnection between the identified sites could be traced by using lineament orientation. All the selected sites belong to the areas of $3 \mathrm{rd}$ and 4th order streams which is a desirable characteristic for the construction of reservoir because the soil in the upstream areas tends to be unstable particularly, in Mizoram as they are sandy in nature. The proposed sites could serve as a supplement to irrigation and

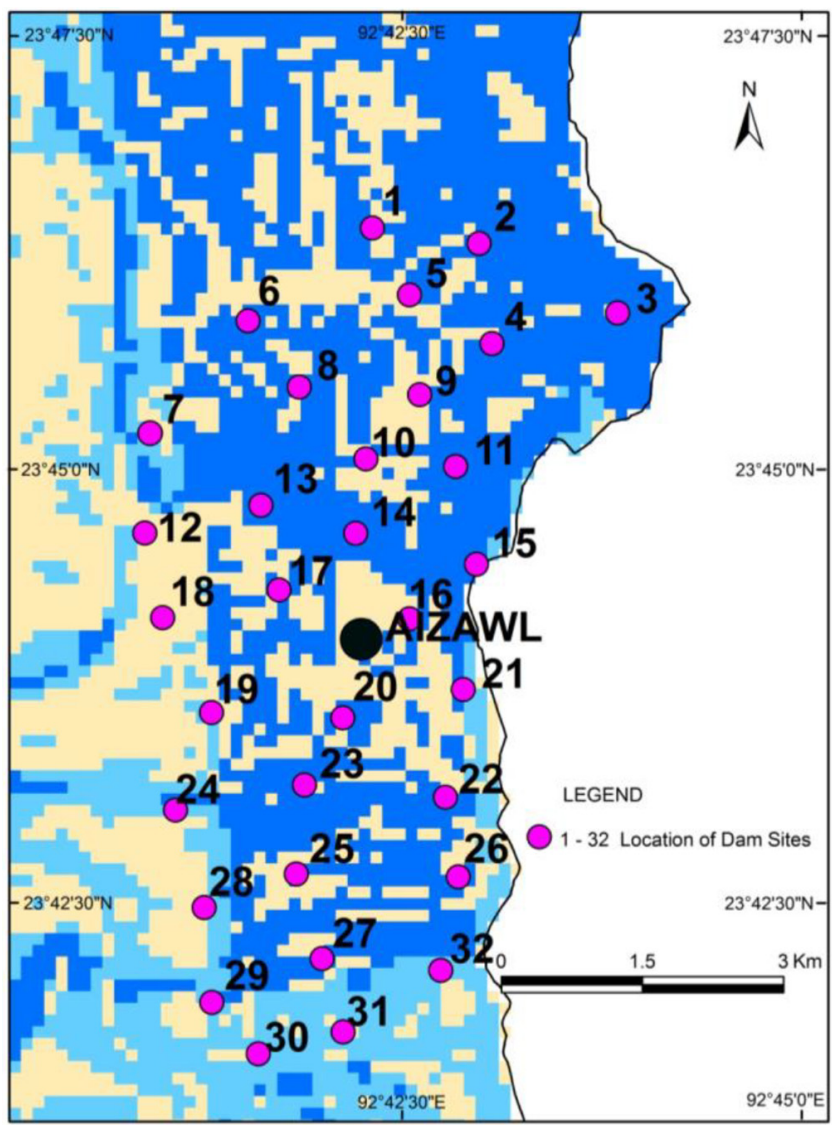

Fig. 4. Site suitability map of water harvesting structures within $4 \mathrm{~km}$ radius of Aizawl city.

the source of drinking water mainly during the lean period. In other districts of Mizoram, wherever the major towns are located within the reach of Tlawng River basin, similar type of methodology could be adopted.

In Mizoram, small RWH structures are more feasible than large RWH structures considering seismic hazards and rapid sedimentation. The topography of the study area being hilly area composed of a large number of narrow valleys which is suitable for construction of RWH.

\section{References}

1. Singhvi AK, Krishnan R. Past and the present climate of India. In: Kale V, eds. Landscapes and Landforms of India; 2014. p. 15-23.

2. Oweis TY, Prinz D, Hachum AY. Rainwater harvesting for agriculture in the dry areas. 1st ed. London, UK: CRC press; 2012. p. 262.

3. Lalhmingliana, Saha G. Identification of suitable dam site: A Survey. Int. J. Comp. Eng. Technol. 2016;7:56-64.

4. Al-Adamat R. GIS as a decision support system for silting water harvesting ponds in the basalt aquifer/NE Jordan. J. Environ. Assess. Policy Manage. 2008;10:189-206. 
5. De Winnaar G, Jewitt G, Horan M. A GIS-based approach for identifying potential runo_harvesting sites in the thukela River basin, South Africa. Phys. Chem. Earth Parts $A / B / C$ 2007;32:1058-1067.

6. Mati B, Bock D, Malesu TM, et al. Mapping the potential of rainwater harvesting technologies in Africa. A GIS overview on development domains for the continent and ten selected countries. Tech. Manual 2006;6:126.

7. Horton RE. Drainage basin characteristics. Trans. Am. Geol. Union 1932;13:350-361.

8. NASA. ASTER Global Digital Elevation Map [Internet]. Available from: https://asterweb.jpl.nasa.gov/gdem.asp.

9. Udaya Bhaskara Rao Ch. Estimation of sediment yield rate in the lower Tlawng River basin, Mizoram. Geographic 2015;10:1-11.

10. Hiroko K, Toshihiko S, Wataru T. Permeability structure and basin analysis of Miyazaki Group, Division of Earth and Planetary Sciences [dissertation]. Kyoto: Kyoto Univ; 2017.

11. Horton RE. Erosional development of streams and their drainage basins: Hydrophysical approach to quantitative morphology. Bull. Geol. Soc. Am. 1945;56:275-370.

12. Gary M, McAFee R, Woli CL. Glossary of Geology. Washington, D.C: American Geological Institute;1972. p. 805.

13. Bates RL, Jackson JA. Glossary of Geology: 3rd eds. Alexandria(VA); 1987. p. 788

14. Singh V, Singh UC. Basin morphometry of Maingra River, District Gwalior, Madhya Pradesh, India. Int. J. Geomat. 2011;1:891-902.

15. Zonunsanga R, Udaya BRC. Shifting cultivation and land degradation in Teirei watershed, Mizoram. Geographic 2013;8:60-67.

16. Vanlaltanpuia T, Chegondi UBR, Rinawma P. A study on relief characteristics and erosion status of Tuirini watershed, Mizoram. Nat. Res. Mngt. Sust. Dev. and Rural Livelihoods 2017;3:1241-1251.

17. Lalduhawma K, Srinivasa Rao K, Udaya BRC. GIS-based morphometric analysis of sub-watersheds at Tut River basin, Mizoram. Adv. Eng. Res. 2018;178:87-93. 